\title{
COMPUTER MODELING OF A TWO-JUNCTION, MONOLITHIC \\ CASCADE SOLAR CELL*
}

M. F. Lamorte and D. Abbott

Research Triangle Institute

\section{ABSTRACT}

The theory and design criteria for monolithic, two-junction cascade solar cells are described. The departure from the conventional solar cell analytical method and the reasons for using the integral form of the continuity equations are briefly discussed. The results of design optimization are presented. The energy conversion efficiency that is predicted for the optimized structure is greater than $30 \%$ at $300 \mathrm{~K}$, AMO and one sun.

The analytical method predicts device performance characteristics as a function of temperature. In this paper, the range is restricted to 300 to $600 \mathrm{~K}$. While the analysis is capable of determining most of the physical processes occurring in each of the individual layers, only the more significant device performance characteristics are presented.

\section{SYMBOLS}

$n$

conversion efficiency, \%

$\mathrm{D}_{\mathrm{ni}}, \mathrm{D}_{\mathrm{pi}}$

electron and hole diffusion coefficient, respectively, in region $i, \mathrm{~cm}^{2} \mathrm{sec}^{-1}$

$\Delta E_{c i}, \Delta E_{v i}$ conduction and valence bandedge discontinuity, respectively, at $\mathrm{x}_{i}$ interface, $\mathrm{eV}$

$\mathrm{E}_{\mathrm{G}}\left(\mathrm{x}_{i}\right)$ bandgap at $\mathrm{x}_{\mathrm{i}}$ interface, $\mathrm{eV}$

$E_{c i}, E_{v i}$ conduction and valence bandedge, respectively, at $x_{i}$ interface, $\mathrm{eV}$

$\mathrm{E}_{\mathrm{FO}}$ equilibrium Fermi level, eV F V-I solar cell curve fill-factor

FThis work was supported by the Avionics Laboratory, Wright-Patterson Air Force Base. Rewriting the computer program to include Fermi-Dirac statistics was supported by the U.S. Department of Energy and Sandia Laboratories, Albuquerque, NM. 


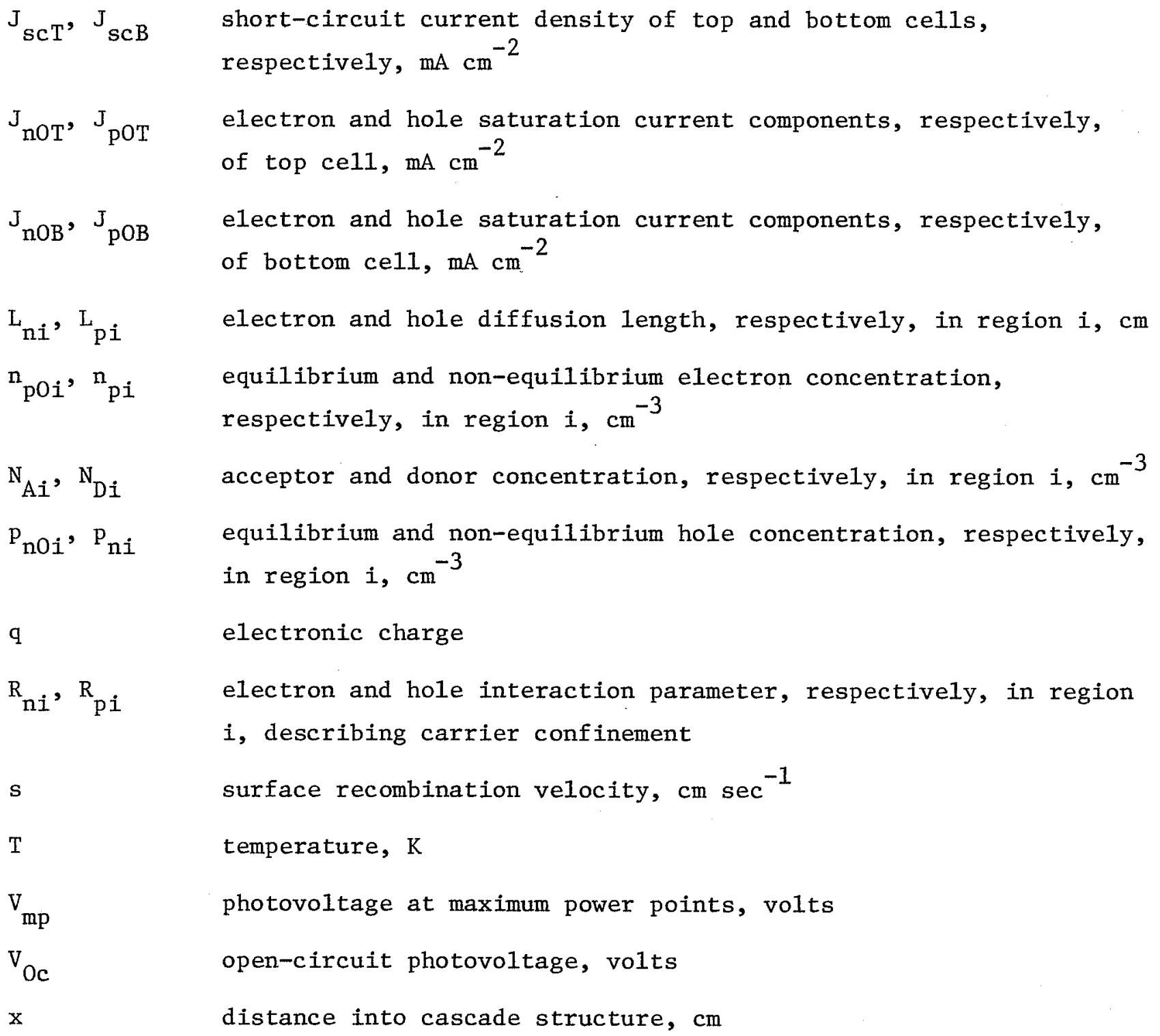

\section{INTRODUCTION}

The characteristics and limitations of silicon solar cells are well known. Maximum theoretical efficiencies for silicon cells range as high as $21 \%$ under AMO spectral conditions $[1,2]$, although experimental values have remained below $18 \%$ at irradiation levels of one sun $[3,4]$. Studies have been conducted to increase efficiency through the reduction of surface reflection loss, the use of $n^{+}-p$ and $p^{+}-n$ structures [5], the establishment of a built-in field in the "dead" surface layer to improve spectral response and to reduce dark current [6], and the provision of a reflective surface [7] and a retarding field at the back contact interface to reduce dark current [8-12]. Each of these improvements has increased silicon cell efficiency, but the gains have not been sufficient to discourage investigations of alternative solar cell materials. Moreover, at high illumination levels and elevated temperatures, the applicability of silicon 
cells is limited by a rapid decrease in efficiency with increasing temperature $[3,4,13]$.

An ideal solar cell material will have a different bandgap energy than silicon and will absorb photons by direct optical transitions. Materials with reasonable diffusion length and direct optical transitions have high efficiency because losses due to incomplete absorption, spectral response, and dark current are improved. If, in addition, the material is metallurgically compatible with other semiconductor materials, monolithic devices may be fabricated with window layers [14] and minority carrier confinement structures. Silicon is difficient with respect to these criteria.

Most prominent among the material alternatives to silicon are the III-V compound semiconductors. Major advantages of these materials are higher theoretical efficiencies and improved temperature performance $[1,2,13]$.

Efficiency calculations for the binary compounds (InP, GaAs, AlSb) with ideal homojunctions and structural characteristics have indicated maximum values of $25 \%$ or more $[1,2,13]$. Although heterojunction cells with GaAs as one of the materials appear to have most promise for actually approaching theoretically predicted efficiency values, it is unlikely that single-junction cells fabricated from III-V compounds will ever achieve efficiency levels above $22 \%$ at $300 \mathrm{~K}$ and a concentration of one sun.

\section{CASCADE (MULTIJUNCTION, MULTIBANDGAP) SOLAR CELL}

Few approaches are available for increasing the conversion efficiency of the single-junction solar cell [15-20]. This arises because the single-junction cell absorbs photons from only a portion of the solar spectrum and it incompletely utilizes the energy of those photons that it absorbs. Three approaches -- the cascade cell, a multiple-cell beam splitting system, and the thermophotovoltaic cell -- have been proposed to increase efficiency above that of the single-junction cell. In this paper, attention is directed to the mono1ithic cascade cell.

The monolithic cascade structure consists of multiple layers of different bandgap materials [21-25]. The properties of III-V compound semiconductors are such that these materials are well suited to the synthesis of monolithic, multiple-junction cells having theoretical efficiency values approximately $50 \%$ higher than single-junction GaAs solar cells. The cascade cell may be fabricated to operate as a two-terminal device, or the cells may be operated separately as a three-terminal device [21]. In this paper, the two-terminal device is discussed.

The monolithic cascade solar cell discussed is a two-junction device, but unlike a mechanically stacked configuration, it avoids the large losses associated with multiple optical interfaces [21-24]. As depicted in Figure 1, the cell consists of wide (top) and narrow (bottom) bandgap junctions joined electrically through a tunnel junction formed as an integral part of the monolithic structure. This multilayer device incorporates the desirable features of heterojunction and graded bandgap designs in a single integrated unit. The 
active layers consist of III-V ternary compounds selected so as to achieve the desired bandgap in each junction as well as to ideally minimize lattice mismatch between the various layers. The cascade structure may be fabricated on a substrate, such as GaAs, using liquid phase epitaxy (LPE) or vapor phase epitaxy (VPE) technology. Compositional grading may be employed between the substrate and the active layers to avoid problems associated with lattice mismatch. Design optimization studies of this structure have resulted in very promising characteristics as described in this paper [21-24]. The optimum bandgap combination, materials and/or alloys used in the active layers, and other design parameters are functions of the operating conditions. The bandgap energies, for example, increase for cells optimized for high temperature operations.

\section{COMPUTER MODELING RESULTS}

In this section we present and discuss some of the results of the computer modeling. The materials selected and the structure design are optimized for operation at $300 \mathrm{~K}$ under AMO spectral conditions and for one sun. While the computer program provides much information relating to terminal characteristics and internal phenomena, only the more significant results are presented in the interest of brevity.

\section{Optimized Band Structure}

The band structure shown in Figure 2 and the corresponding listing of the design parameters presented in Table 1 provide the optimized structure obtained from the computer modeling--i.e., the design parameters giving the maximum efficiency for operation at $300 \mathrm{~K}$, AMO, and one sun [21-24]. Region 1 serves as the window layer, regions 2 and 3 form the top cell homojunction, regions 4 and 5 the tunnel junction, regions 6 and 7 the bottom cell homojunction, and region 8 the substrate. In the following discussion, the AlGaAs-GaInAs materials combination is selected. While the structure contains seven active layers, the loss due to incomplete absorption in the top cell is negligible so that the tunnel junction is optically inactive. However, if the tunnel junction bandgap is made smaller than the top cell bandgap, it will become optically active and produce a photovoltage that is in opposition to the photovoltage produced by the top and bottom cells. The effect of the photovoltage generated in the tunnel junction in such a design may be minimized by making the $\mathrm{n}^{+}$and $\mathrm{p}^{+}$ tunnel junctions less than $0.5 \mu \mathrm{m}$. When the $\mathrm{n}^{+}$and $\mathrm{p}^{+}$regions exceed $1.0 \mu \mathrm{m}$ and the bandgap value is less than $0.3 \mathrm{eV}$ less than the top cell, the cascade cell efficiency is reduced to a value lower than the top cell operating as a singlejunction cell. Therefore, to insure maximum efficiency, the tunnel junction bandgap should be equal to or greater than the top cell bandgap.

The window layer shown has a built-in field intensity of $3000 \mathrm{Vcm}^{-1}$, but the influence of the field on efficiency is small because it is thin (i.e., $0.1 \mu \mathrm{m})$, its bandgap is significantly larger than the top cell bandgap, and the conduction bandedge discontinuity, $\Delta \mathrm{E}_{\mathrm{c}}$, confines minority electrons to region 2 . The confinement markedly reduces the dark current while the field intensity in the window layer plays a minor role in reducing dark current. Photon absorption 
in the window layer is minimized for maximum efficiency through the selection of its thickness and bandgap value at the surface.

Similarly, the valance band discontinuity, $\Delta \mathrm{E}_{\mathrm{v} 3}$, at $\mathrm{x} 3$ confines minority holes to region 3, thereby increasing spectral response and reducing the hole contribution to dark current. While $\Delta \mathrm{E}_{\mathrm{v} 3}$ is influenced by the choice of the tunnel junction bandgap, the tunnel junction bandgap is made as small as possible because of the difficulty in obtaining a tunnel junction in wider bandgap materials. Our results show, however, that for effective carrier confinement, the minority carrier bandedge discontinuities surrounding a homojunction solar cell should be $6 \mathrm{kT}$ to $7 \mathrm{kT}$. Beyond $7 \mathrm{kT}$, the dark current approaches an asymtotic value. Similar statements may be made for $\Delta \mathrm{E}_{\mathrm{c} 5}$ and $\Delta \mathrm{E}_{\mathrm{v} 7}$ with respect to the lower bandgap cell [21-24].

In order for the minority carrier bandedge discontinuities to be effective in reducing dark current, the minority carrier diffusion lengths must be greater than their respective layer thicknesses. Typically in the materials considered here, the diffusion lengths are several times greater than the layer thicknesses. The computer program determines the optimum thickness to obtain maximum efficiency.

The two-terminal cascade cell requires that the terminal current must pass through each of the three junctions. This requirement strongly affects the choice of materials, predominantly through the bandgap combination. The terminal operating current is obtained by maximizing conversion efficiency.

The band structure that results from the modeling makes the top and bottom cells "potential wells" for minority carriers produced by photon absorption as well as for the dark current injected carriers [21]. This condition is obtained from the integral form of the continuity equation used in the analysis which results in the V-I solar cell equation and because in the analytical treatment, the band structure details described above are incorporated. Thus, in one relationship most of the significant parameters which strongly affect conversion efficiency are included.

\section{Voltage-Current Relationship}

The analytical method employed here gives the V-I solar cell equation for the cascade cell, including the voltage drop across the tunnel junction which is required to conduct the terminal current. Should the tunnel junction produce a photovoltage, the sum of the photovoltage and the voltage drop required to conduct the terminal current, in the absence of a photovoltage, must be subtracted from the sum of the top and bottom cell photovoltages. The V-I relationship of the cascade cell is used to calculate the power at the maximum power point from which the conversion efficiency is obtained. This is the focal point of the analytical method and the corresponding computer program. In an optimally designed cell, the current at the maximum power point of the cascade cell is nearly identical to the current at the maximum power points of the V-I curves of the individual cells. This manifests itself through nearly equal short-circuit currents and relatively small differences in dark currents of top and bottom cells over a wide range of temperature. 
The temperature dependencies of the material parameters (mobility, bandgap, carrier concentration, relative occupation of electrons in direct and indirect conduction band minima, etc.) are included in the computer program. Temperature effects on the solar cell $\mathrm{V}-\mathrm{I}$ curve are manifest through changes in $\mathrm{V}_{\mathrm{mp}}, \mathrm{V}_{0 \mathrm{c}}, \mathrm{F}$, and to a lesser degree, $\mathrm{J}_{\mathrm{Sc}}$. While calculations were performed at surface recombination velocities of $0,10^{6}$, and $10^{7} \mathrm{~cm} \mathrm{sec}-1$, all calculations are represented for $10^{6} \mathrm{~cm} \mathrm{sec}-1$.

The family of V-I curves for the optimized cascade cell is shown in Figure 3, with temperature a parameter, and for a $10^{6} \mathrm{~cm} \mathrm{sec}-1$ surface recombination velocity. It is seen that the photovoltage at the maximum power point and the open-circuit voltage are strong functions of temperature, while the short-circuit current is nearly independent of temperature. The shape and the temperature dependence of the cascade solar cell $\nabla-I$ curves exhibit behavior similar to that of a single solar cell with a short-circuit current density of approximately $30 \mathrm{~mA} \mathrm{~cm}$, an open-circuit voltage of 1.75 volts, and an apparent bandgap value of approximately $2.57 \mathrm{eV}$ (i.e., the sum of the bandgaps of top and bottom cells). Each point on the V-I curve represents the sum of the photovoltaic voltages of top and bottom cells minus the tunnel junction voltage drop, all for a given terminal current. These curves show that the open-circuit voltage is approximately 1.75 times that of a single-junction GaAs solar cell. and more than three times that of Si cells.

Lower surface recombination values increase the short-circuit current, and higher values of recombination reduce the current while photovoltage changes are considerably smaller because of their logarithmic dependence on current. This behavior is also observed on a single-junction solar cell.

\section{Bandgap Combination}

To illustrate the influence of bandgap values on efficiency, allow either the top or bottom bandgaps to change while maintaining the other constant. Figure 4 shows the efficiency vs. the top cell bandgap while the bottom bandgap is held constant at $0.954 \mathrm{eV}$; Figure 5 allows the bottom bandgap to change while the top cell bandgap is held constant at $1.62 \mathrm{eV}$.

In Figure 4, maximum efficiency occurs at a bandgap value of $1.62 \mathrm{eV}$ for the top cel1. For a surface recombination velocity lower than $10^{6} \mathrm{~cm} \mathrm{sec}-1$, the optimum bandgap value shifts to higher values, and for higher recombination velocity the shift is to lower bandgap values. On either side of $1.62 \mathrm{eV}$, the efficiency drops rapidly. In the low bandgap region, the slope is relatively constant and its value is approximately $46 \% / \mathrm{eV}$, while beyond $1.7 \mathrm{eV}$, the slope is approximately $30 \% / \mathrm{eV}$. The slope in the low bandgap region is more than $50 \%$ greater than it is in the high bandgap region.

Maximum efficiency in Figure 5 occurs at $0.954 \mathrm{eV}$, representing the optimum bottom cell bandgap value. This optimum value is insensitive to surface recombination velocity and to air mass from AMO to AM5 [26]. On either side of this maximum, the efficiency decreases with nearly constant slopes. The slope below $0.954 \mathrm{eV}$ is $17.5 \% / \mathrm{eV}$, which is considerably smaller than the value above $0.954 \mathrm{eV}$ 
which is $49 \% / \mathrm{eV}$. The former is lower while the latter is higher than either slope given in Figure 4.

The curves in Figures 4 and 5 show that decreasing the bottom cell bandgap from its optimum value, while maintaining all other design parameters at their optimum values, results in a small decrease in cascade efficiency. However, increasing the top cell bandgap from its optimum value produces a larger decrease in efficiency. If either the bottom cell bandgap is increased or the top cell bandgap is decreased, while holding all other design parameters at their optimum values, an equally sharp drop in efficiency results. This is substantiated by comparing the slope in Figure 4 below $1.62 \mathrm{eV}$ with the slope in Figure 5 above $0.954 \mathrm{eV}$. The slopes are nearly equal, being $46 \% / \mathrm{eV}$ for the former and $49 \% / \mathrm{eV}$ for the latter.

Reducing the bottom cell bandgap serves to increase the photon flux absorbed, to increase the short-circuit current, and to reduce the photovoltage. This does not change the top cell terminal operating current significantly. Therefore, the reduction in efficiency arises through a smaller contribution to the cascade efficiency from the bottom cell. Increasing the top cell bandgap reduces the photon absorption in the top cell, reducing its short-circuit but increasing its photovoltage. There is a reduction in efficiency in the bottom ce11, because of a mismatch in maximum power point operating current between top and bottom cells, but a smaller decrease in the top cell.

\section{Layer Thickness}

The behaviors of the top and bottom cells with respect to the thickness of the $\mathrm{n}$ - and p-type regions are similar. While in this presentation the bottom cell behavior is discussed, the results apply equally as well to the top cell behavior. Figure 6 shows the effect on efficiency when varying the ratio of the p-type layer to the total thickness of the p-plus n-layers of the bottom cell. The efficiency exhibits a peak at a ratio of 0.35 for the bottom cell. In the top cell the peak efficiency occurs for a ratio of 0.445 . For low values of the ratio, the rate of increase of efficiency is greater in magnitude than the magnitude of the rate of decrease for high ratios. This results because for low ratios, the incomplete absorption loss predominates and serves to significantly reduce efficiency.

The form of dark current components is given by

$$
\mathrm{J}_{\mathrm{nO} i}=\mathrm{q} \frac{\mathrm{D}_{\mathrm{ni}}}{\mathrm{I}_{\mathrm{ni}}} \mathrm{n}_{\mathrm{pO} \mathrm{i}_{\mathrm{ni}}}
$$

for the electron contribution and

$$
\mathrm{J}_{\mathrm{pOi}}=\mathrm{q} \frac{\mathrm{D}_{\mathrm{pi}}}{\mathrm{L}_{\mathrm{ni}}} \mathrm{p}_{\mathrm{nOi}}{ }_{\mathrm{pi}}
$$

for holes, where the subscript $i$ is assigned the value $T$ or $B$ to denote the top 
and bottom cells, respectively. The interaction parameter $R_{\mathfrak{n} i}$, relating to electron confinement in the p-type region, increases with increasing p-type ratio, resulting in increased contribution from photoexcited electrons to short-circuit current (i.e., spectral response) and an increased contribution to dark current from injected electrons. Moreover, as the p-type ratio increases, the corresponding $n$-type ratio, $\left(x_{7}-x_{6}\right) /\left(x_{7}-x_{5}\right)$, decreases, resulting in $R_{p B}$ decreasing. Therefore, the hole contribution to normalized spectral response and dark current in the n-region also decrease as shown in Figures $6(\mathrm{~b})$ and $6(\mathrm{c})$. Figure 6(c) shows the electron normalized spectral response in the p-type region to be lower than the hole normalized spectral response for thin p-regions. For thick p-regions, the reverse is true.

It should be noted that maximum efficiency occurs in the neighborhood where the electron and hole contributions to dark current are equal. This is typical of single- or multijunction behavior where the cell structures are optimized.

The second set of calculations allows the total thickness of the $n-p l u s$ the p-region to increase. Figure 7 relates to the bottom cell. The ratio of the p-layer to the total thickness of the homojunction is maintained at the optimum ratio obtained and shown in Figure 6(a). For maximum efficiency, the optimum total thickness of the top homojunction obtained is $3.4 \mu \mathrm{m}$, as shown in Figure 7(a); and for the top cell it is shown to be $1.8 \mu \mathrm{m}$. It is observed that the efficiency decreases sharply for values lower than the optimum thickness in Figure 7(a). This occurs because the incomplete absorption loss predominates in both $\mathrm{n}$ - and $\mathrm{p}$-type regions for smaller thickness values, but becomes negligible for large thickness values. The dark current components increase sharply for increasing values, and beyond the optimum thickness the rate of increase becomes smaller, as shown in Figure $7(\mathrm{~b})$. Also, while incomplete absorption is the major loss for small thickness values, both the electron and hole normalized spectral responses are very high due to the thin $\mathrm{n}$ - and p-regions, as shown in Figure $7(\mathrm{c})$. The absolute spectral response, of course, increases as the homojunction regions become thicker.

\section{SUMMARY AND CONCLUSIONS}

The solution to the integral form of the continuity equation results in the V-I solar cell expression for each of the component cells as well as for the cascade cell as a unit. The computer program determines the design parameters for maximum efficiency. The analysis predicts a cascade cell conversion efficiency in excess of $31 \%$ at $300 \mathrm{~K}$, AMO, and one sun.

The cascade V-I solar cell curve behaves as if the device is fabricated from a single $\mathrm{p}-\mathrm{n}$ junction. The voltage at the maximum power point and the opencircuit voltage exhibit values that suggest a bandgap value equal to the sum of the bandgaps of the top and bottom cells. In contrast, the current at the maximum power point and the short-circuit current values are more characteristic of the top cell bandgap.

The computer modeling predicts that maximum efficiency does not occur for maximum short-circuit current or for minimum dark current, but occurs for a set of design parameters between these extremes. Maximum efficiency occurs for thin 
window layers $<0.1 \mu \mathrm{m}$. The conduction bandedge discontinuity at the window layer heterointerface has a marked effect on efficiency and results in the window layer built-in field having a small influence.

Efficiency, photovoltage, dark current, fill-factor, and spectral response are shown to exhibit temperature dependencies similar to those of singlejunction solar cells.

\section{REFERENCES}

1. J. J. Loferski, J. App1. Phys., 27, 96 (1956).

2. J. J. Wysocki and P. Rappaport, J. App1. Phys. 31, 571 (1960).

3. E. L. Burgess and J. G. Fossum, IEEE Trans. Electron Devices, ED-24, 433 (1977).

4. J. G. Fossum, ERDA Photovoltaic Concentrator Systems Workshop, Scottsdale, $\mathrm{AZ}$, May 24, 1977, U. S. Dept. of Energy, Washington, D.C.

5. H. J. Hovel, Solar Cells, Vol. II, Semiconductors and Semimetals, Ed.: A. C. Beer and R. K. Willaxdson, Academic Press, Inc., New York, N.Y., $(1976)$.

6. J. Lindmayer and J. F. Allison, Comsat Tech. Rev. 3, 1 (1973).

7. D. Redfield, App1. Phys. Lett. 25, 647 (1974).

8. J. Mandelkorn and J. H. Lamneck, Jr., J. Appl. Phys. 44, 4785 (1973).

9. M. P. Godewski, C. R. Baraona, and H. W. Brandhorts, Jr., 10th Photovoltaic Specialists Conf., IEEE, Palo Alto, CA, November 13-15, 1973.

10. H. W. Brandhorst, Jr., C. R. Baraona, and C. K. Swartz, 10th Photovoltaic Specialists Conf., IEEE, Palo Alto, CA, November 13-15, 1973.

11. J. Mandelkorn, J. H. Lamneck and L. R. Scudder, 10th Photovoltaic Specialists Conf., IEEE, Palo Alto, CA, November 13-15, 1973.

12. J. G. Fossum, IEEE Int. Electron Devices Meeting, Washington, D.C. (1975).

13. H. J. Hove1, IBM J. Res. Dev. 22, 112 (1978).

14. J. M. Wooda11 and H. J. Hove1, App1. Phys. Lett. 21, 379 (1972).

15. N. S. Alvi, C. E. Backus, and G. S. Masden, 12th Photovoltaic Specialists Conf., IEEE, Baton Rouge, LA, November 15-18, 1976.

16. R. L. Moon, L. W. James, H. A. VanderPlas, Y. G. Chai and G. A. Antypas, 13th Photovoltaic Specialists Conf., IEEE, Washington, D.C., June 5-8, 1978. 
17. G. W. Masden and C. E. Backus, 13th Photovoltaic Specialists Conf., Washington, D.C., June 5-8, 1978.

18. W. Blocker, Proc. IEEE 66, 104 (1978).

19. E. D. Jackson, Trans. Conf. on the Use of Solar Energy (Tucson, 1955, University of Arizona Press, AZ) 5, 122 (1958).

20. L. W. James, IEEE Int. Electron Devices Meeting, Washington, D.C., December 1-3, 1975.

21. Solar Cel1 Design Study: Final Report, Contract No. F33615-76-C-1283, Research Triangle Institute, February 1977.

22. M. F. Lamorte and D. Abbott, 12th Photovoltaic Specialists Conf., IEEE, Baton Rouge, LA, November 15-18, 1976 ("Analysis of a Two-Junction Monolithic Solar Cell in a Structure Using $\mathrm{Al}_{\mathrm{u}} \mathrm{Ga}_{1-\mathrm{u}} \mathrm{As}$ and $\mathrm{Ga}_{\mathrm{v}} \mathrm{In}_{1-\mathrm{v}} \mathrm{As}$ ").

23. M. F. Lamorte and D. Abbott, DOE Photovoltaic Concentrator Systems Workshop, Scottsdale, AZ, May 24-26, 1977.

24. M. F. Lamorte and D. Abbott, 13th Photovoltaic Specialists Conf., IEEE, Washington, D.C., June 5-8, 1978.

25. L. M. Fraas and R. C. Knechtli, 13th Photovoltaic Specialists Conf., IEEE, Washington, D.C., June 5-8, 1978.

26. M. F. Lamorte and D. Abbott, to be published in Solid State Electronics. 
TABLF I . - DESIGN PARAMETERS OF OPTIMIZED BANDSTRUCTURE

\begin{tabular}{|c|c|c|c|}
\hline DESIGN PARAMETER & $300 \mathrm{~K}$ & DESIGN PARAMETER & $300 \mathrm{~K}$ \\
\hline$E_{G}(0)$ & $1.83 \mathrm{ev}$ & $x_{1}$ & $0.1 \mu \mathrm{m}$ \\
\hline$E_{6}\left(x_{1}\right)$ & 1.80 & $x_{2}-x_{1}$ & 0.8 \\
\hline$E_{G}\left(X_{2}\right), E_{G}\left(X_{3}\right)$ & 1.62 & $x_{3}-x_{2}$ & 1.0 \\
\hline$E_{G}\left(X_{4}\right), E_{G}\left(X_{5}\right)$ & 1.62 & $x_{4}-x_{3}$ & 0.1 \\
\hline$E_{G}\left(X_{6}\right), E_{G}\left(X_{7}\right)$ & 0.954 & $x_{5}-x_{4}$ & 0.1 \\
\hline$E_{G}\left(X_{8}\right)$ & 1.439 & $x_{6}-x_{5}$ & 1.2 \\
\hline$E_{F o}-E_{v 1}$ & 0.07 & $x_{7}-x_{6}$ & 2.2 \\
\hline$E_{q_{0}}-E_{v 2}$ & 0.129 & $\mathrm{~N}_{\mathrm{A} 1}$ & $10^{18} \mathrm{~cm}^{-3}$ \\
\hline$E_{\mathrm{CB}}-E_{\mathrm{Fo}}$ & 0.037 & $N_{A 2}, N_{03}$ & $10^{17}$ \\
\hline$E_{04}-E_{F o}$ & -0.242 & $\mathrm{~N}_{\mathrm{D4}}, \mathrm{N}_{\mathrm{A5}}$ & $10^{20}$ \\
\hline$E_{F o}-E_{v 5}$ & 0.004 & $N_{A G} \cdot N_{D 7}$ & $10^{17}$ \\
\hline$E_{F 0}-E_{v 6}$ & 0.119 & $\mathrm{~N}_{\mathrm{D8}}$ & $10^{17}$ \\
\hline$E_{c 7}-E_{F_{0}}$ & 0.037 & & \\
\hline$E_{c 8}-E_{F_{0}}$ & 0.061 & & \\
\hline$\Delta E_{c 1}$ & 0.239 & & \\
\hline$\Delta E_{v 1}$ & 0.059 & & \\
\hline$\Delta E_{\mathrm{c} z}$ & 0.279 & & \\
\hline$\Delta E_{\mathrm{v} 3}$ & 0.279 & & \\
\hline$\Delta E_{t 5}$ & 0.781 & & \\
\hline$\Delta E_{v 5}$ & 0.115 & & \\
\hline$\Delta E_{c 7}$ & 0.024 & & \\
\hline$\Delta E_{\mathrm{v} 7}$ & 0.461 & & \\
\hline
\end{tabular}

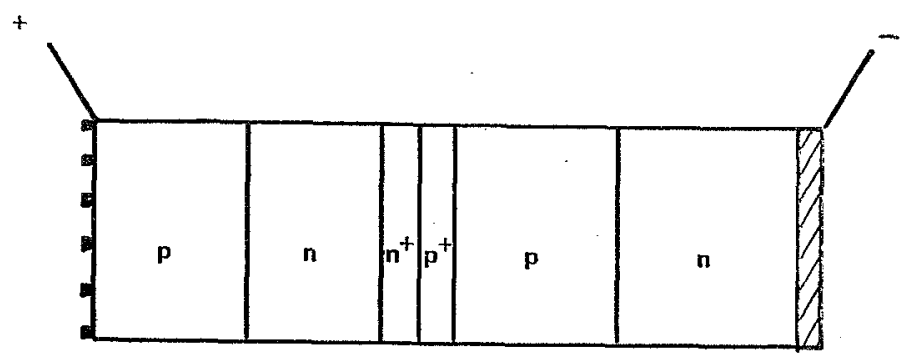

(a) PHYSICAL STRUCTURE

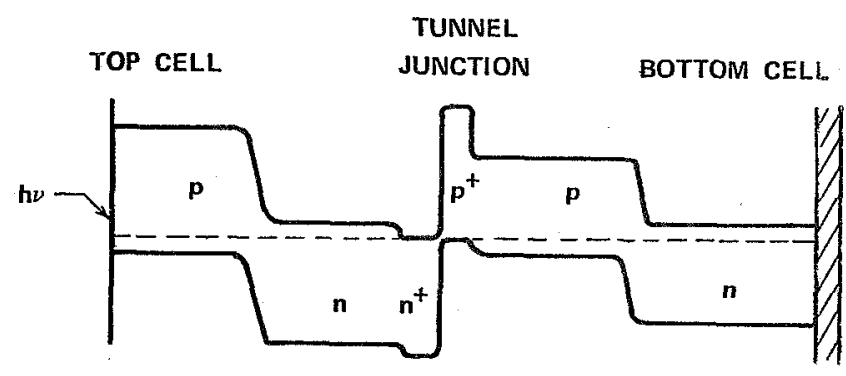

(b) ENERGY BAND STRUCTURE

Figure 1. - Monolithic two-junction solar cell. 


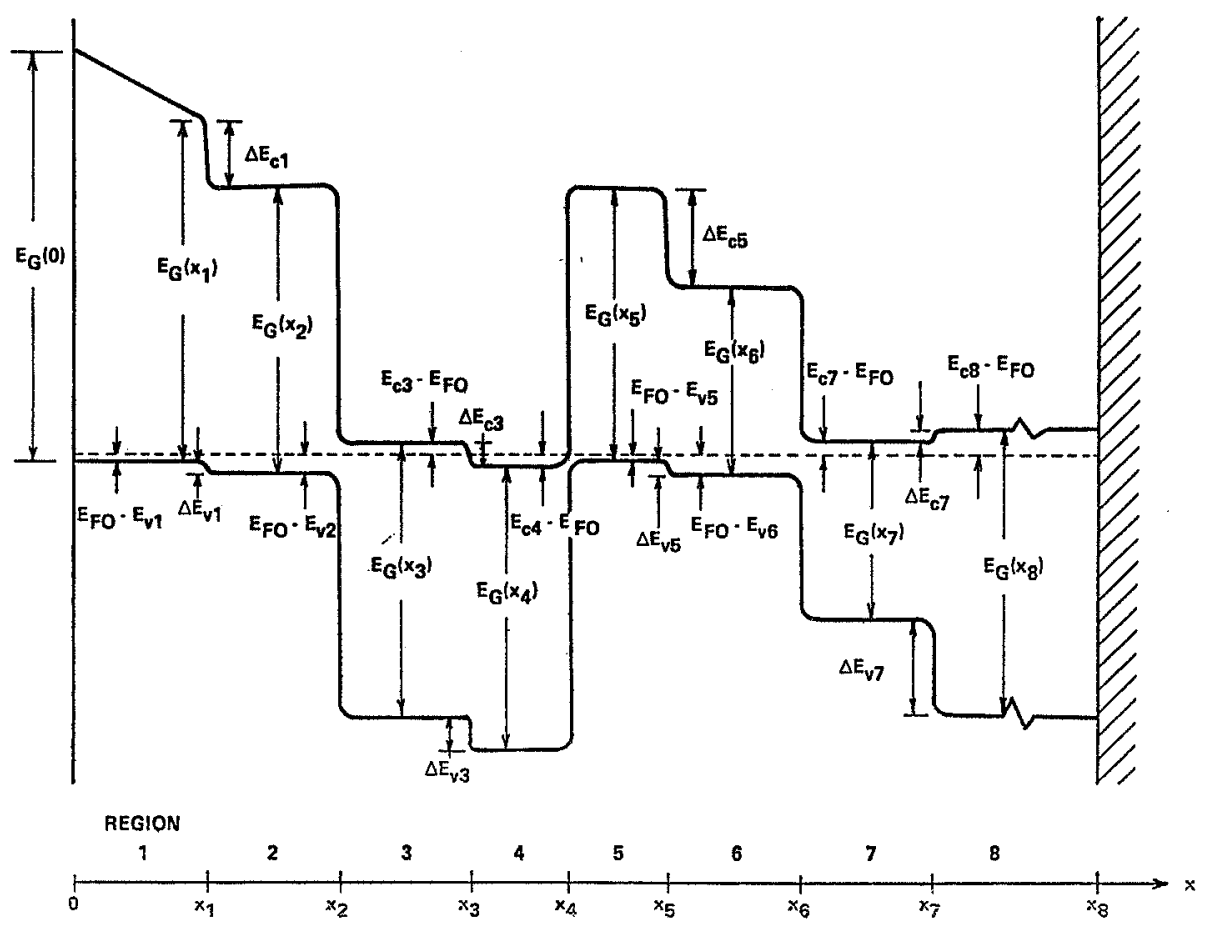

Figure 2.- Band structure of two-junction, voltage-aiding, two-terminal cascade solar cell.

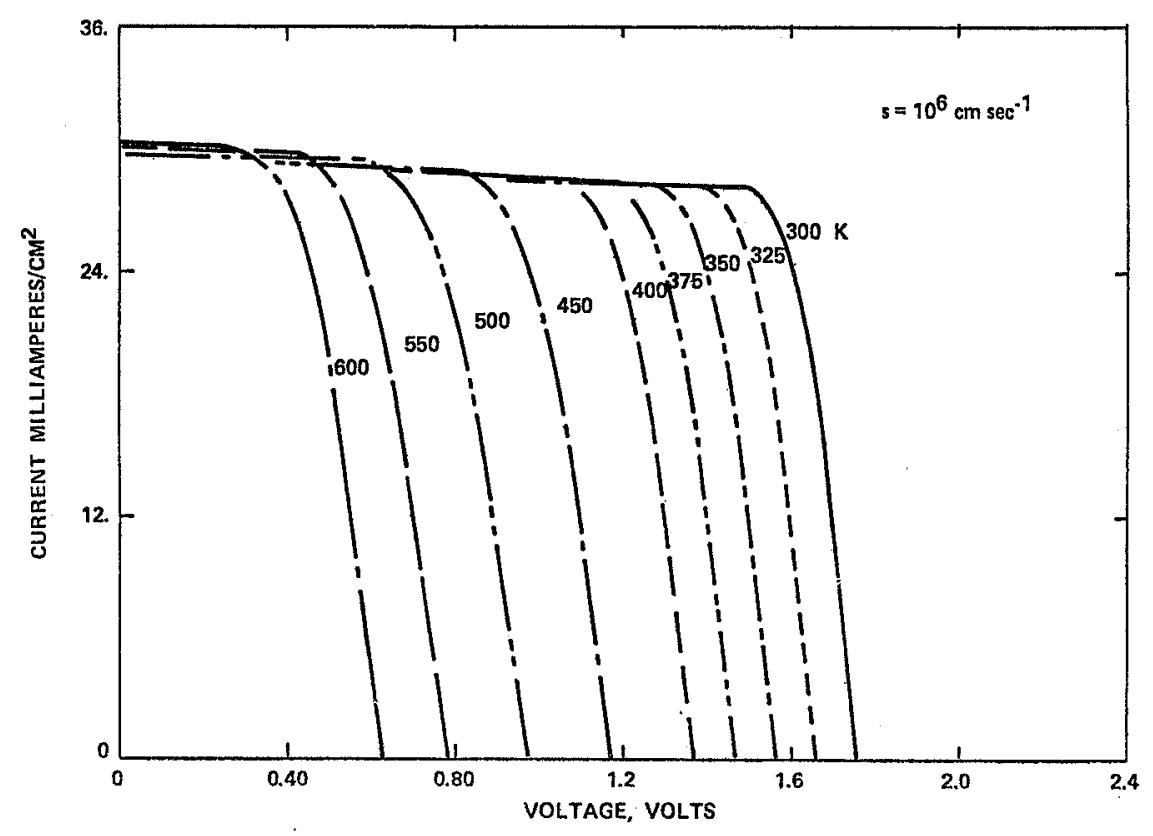

Figure 3. - Cascade solar cell V-I curve with temperature a parameter and for $s=10^{6}$ $\mathrm{cm} \mathrm{sec}{ }^{-1} \mathrm{AMO}$ on a structure optimized for $300 \mathrm{~K}$ operation and AMO. 


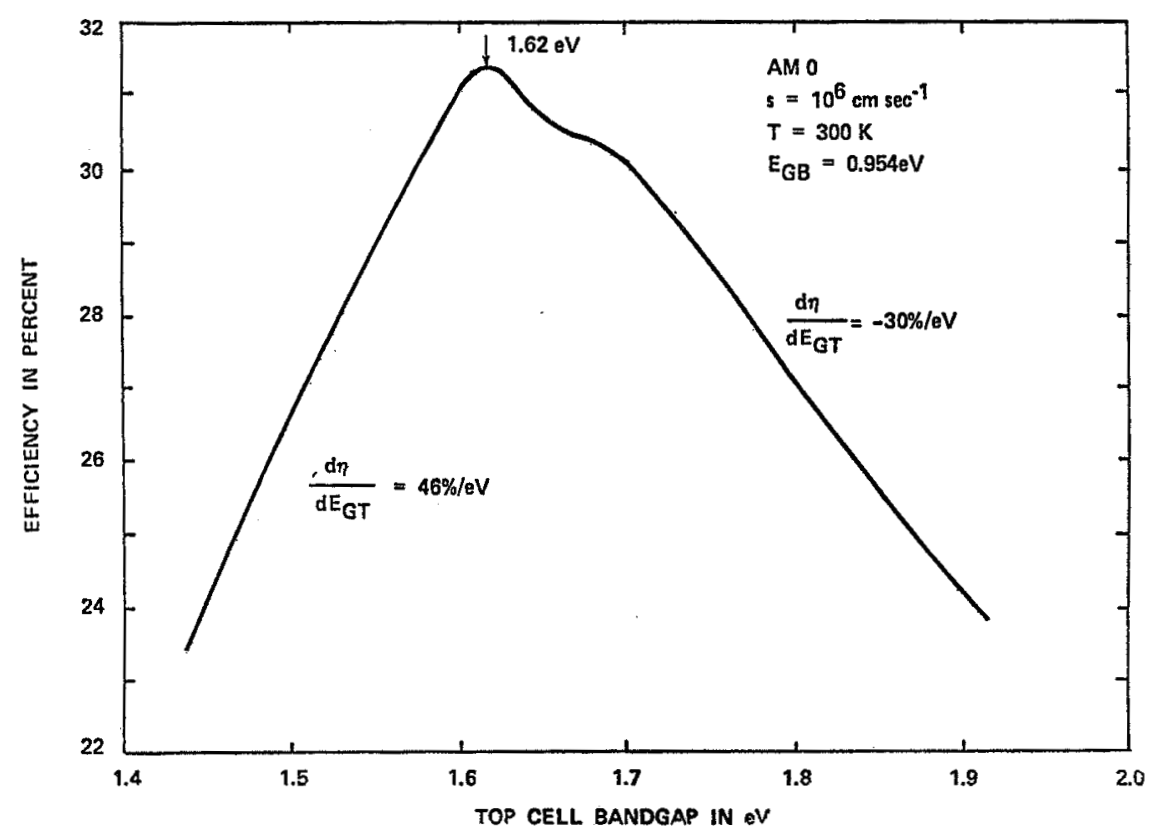

Figure 4. - Conversion efficiency as function of bandgap of top cell for optimized structure.

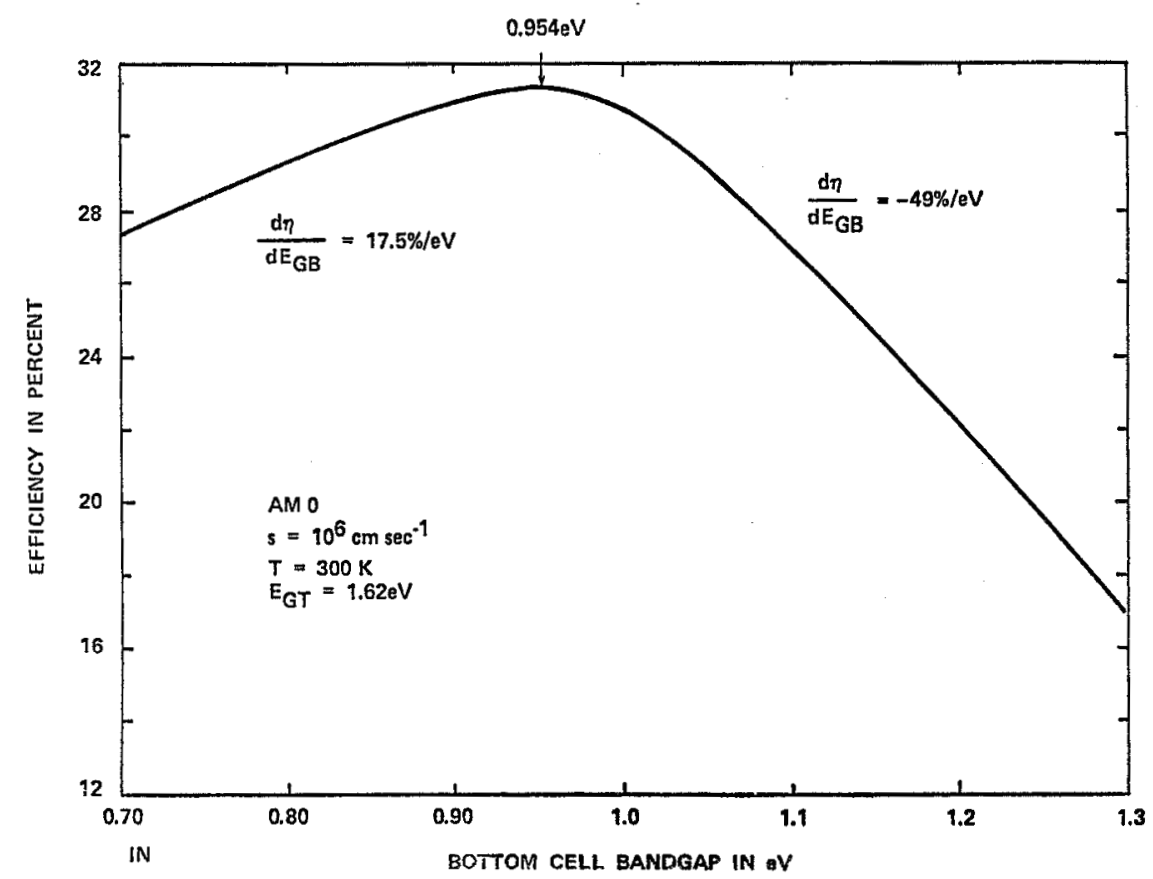

Figure 5. - Conversion efficiency as function of bandgap of bottom cell for optimized structure. 


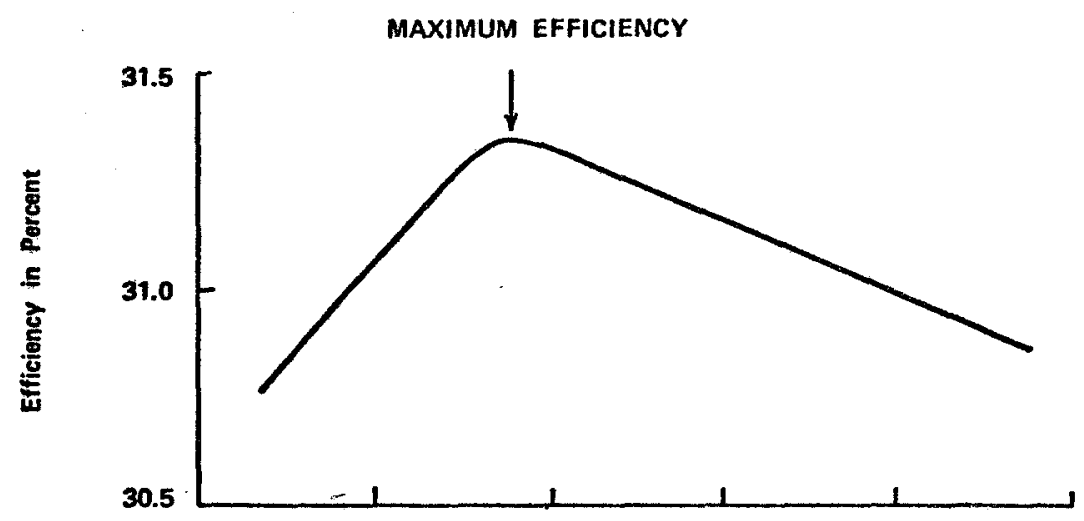

(a)

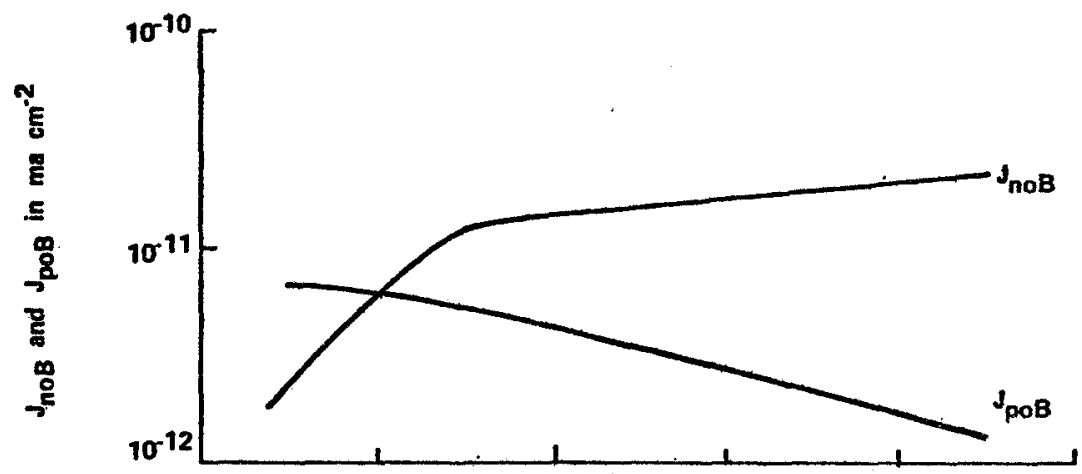

(b)

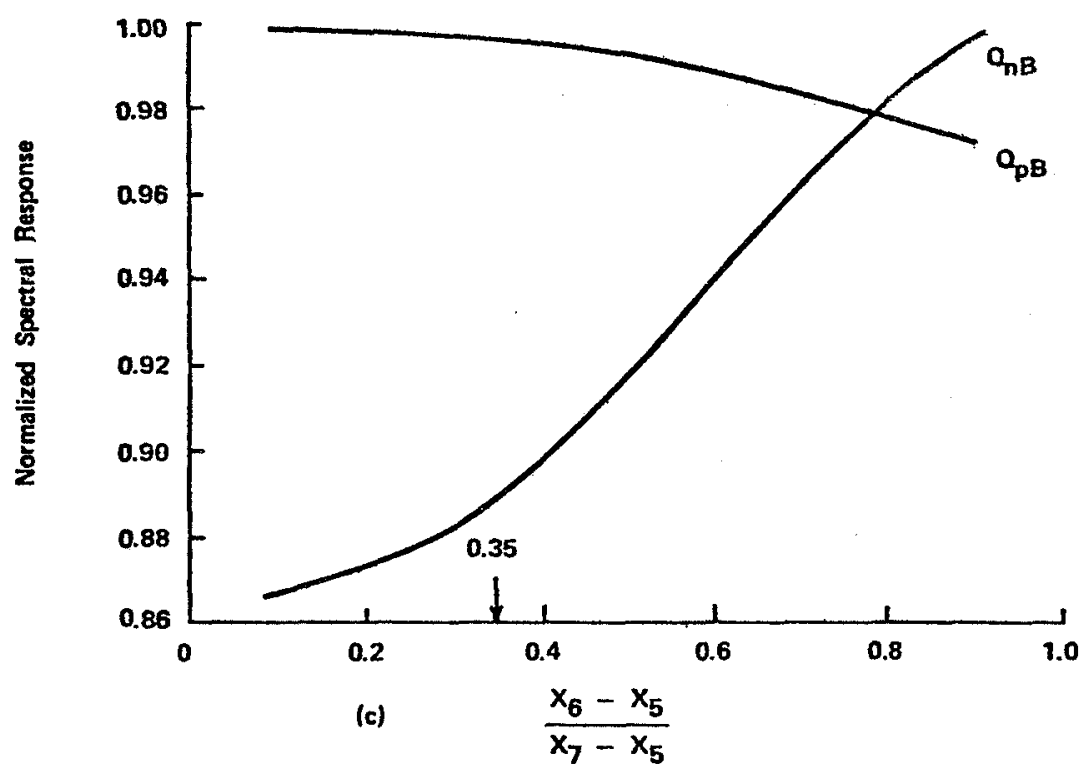

Figure 6. (a) Cascade cell efficiency, (b) electron and hole saturation current values of the bottom cell, and (c) electron and hole normalized spectral response of the bottom cell vs. the ratio of the p-layer thickness to the total thickness of the bottom ce11 homojunction. 

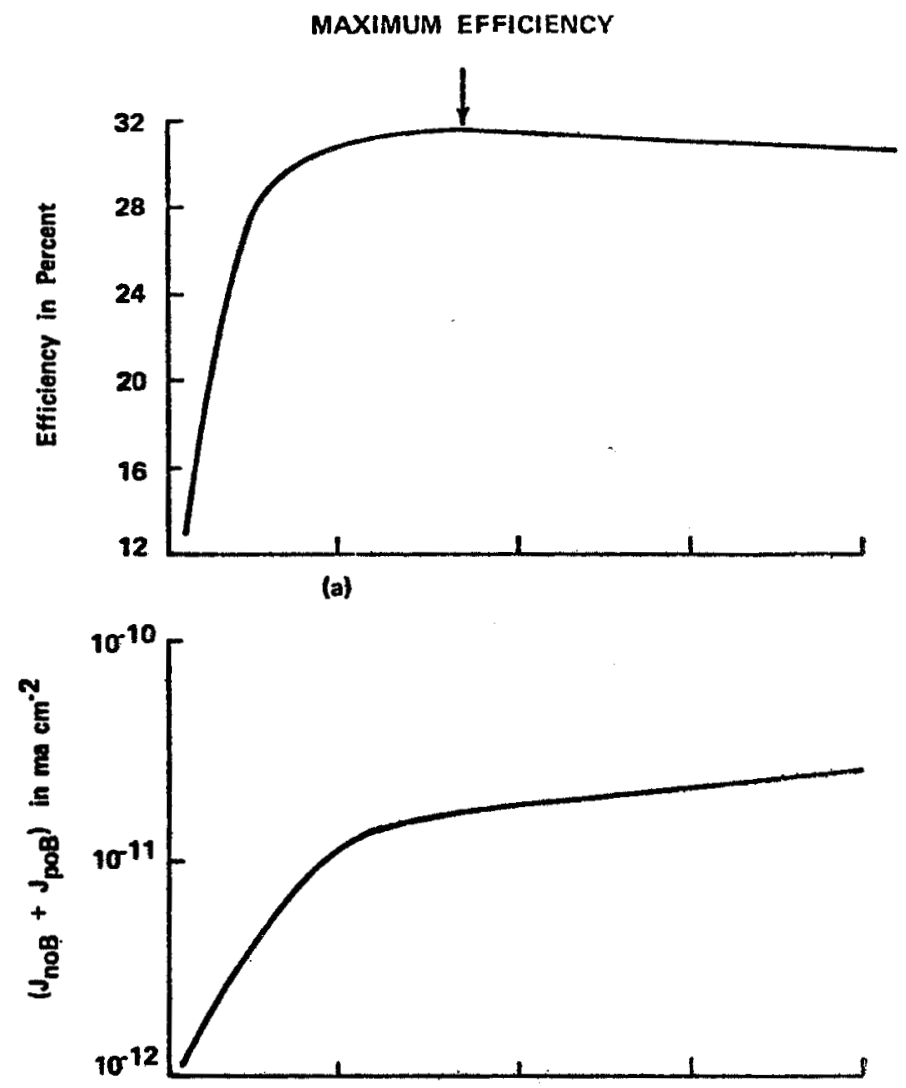

(b)

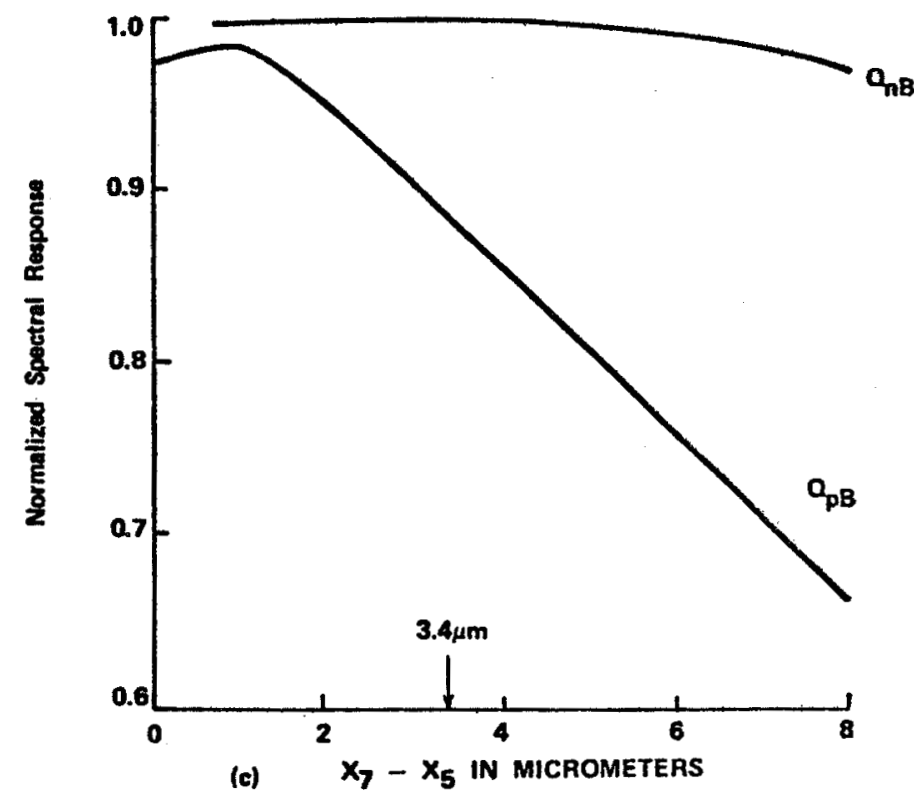

Figure 7. (a) Cascade cell efficiency, (b) total saturation current of the bottom cell, and (c) electron. and hole normalized spectral response of the bottom cell vs. the total thickness of the bottom cell homojunction. 